\title{
The introduction of an information technology project: personal computing in the classroom
}

\author{
David Jones \\ Scotch College \\ Adelaide \\ South Australia
}

\begin{abstract}
Scotch College is the first school in South Australia to introduce, on a large scale, notebook computers to its students. Each Year 7 and 8 student is expected to possess a notebook computer to be used as their own personal, portable computer at school and at home. The aim is to change the emphasis in our teaching methodologies to a more child-centred approach in which students can take greater control over their learning, and to ensure that they can take full advantage of the emerging global information technologies. The notebook is not intended to replace pen-and-paper, but to help create a powerful learning environment. This paper details the planning the school went through, some hurdles which had to be overcome, the training of staff, the impact on the curriculum and the setting up of an infrastructure to enable the notebooks to be efficiently used.
\end{abstract}

Main conference themes: flexible learning, learner centred learning, methodologies, visions

Educational areas: primary education, secondary education

Study topics:

Secondary keywords: classroom practice, curriculum development, innovation, portable computers, technical innovation 


\section{INTRODUCTION}

In 1994 Scotch College, an R-12 private coeducational school in Adelaide, South Australia, introduced notebook computers at Year 7. All 80 students in this year group were expected to have a notebook to be used as their own personal, portable computer at school and at home. Scotch is the first school in this state to follow the trend which has begun in schools in Victoria, but with more information technology focus. The notebooks are leased by parents from the school over a three year period. The college provides a network, remote access and specialized computer laboratory infrastructure.

This innovation is seen to herald a new era in education at this school, whereby access to information in digital form often will become an integral part of the teaching strategies of all teachers in the school. The notebooks "have the potential to act as a catalyst in altering our whole approach to the teaching/learning process" (Principal of Scotch, Mr Ken Webb). It is not intended that computers replace pen-and-paper, but that these will add an extra dimension to education, making it much broader, more flexible and child centred. The notebook project is one key strand of the school's wider strategic plan to access and exploit information technologies in an R-12 learning environment where technological competencies have been identified as a new basic, central to a 21 st century curriculum.

\section{MODELS OF EDUCATIONAL COMPUTING}

\section{The limitations of central computer laboratories}

In recent years the computer's ease of use and power has opened up learning. However, there has still been a major limitation to their use in schools, namely accessibility. Scotch, like many schools, has used computer labs into which teachers will book their classes for a specific number of special lessons. Experience shows that this irregular use does not develop the basic skills needed for efficient use and that new-found knowledge is not necessarily transferred back to the classroom. The teacher may find that it has really been a computing lesson to the students, not a mathematics/history/language lesson.

\section{Saturation computing}

An exciting step forward was made in 1991 by River Oaks Public School, Ontario, Canada, a K-8 school which has made a very large investment in computer technology with one desktop computer for every three students. Their vision is that the technology is 'the raw material from which powerful tools for learning can be created to engage, enable and empower students' [1]. 
Working on the philosophy that 'the computer may be the most naturally integrative tool that students and teachers have available', their fully networked computers are classroom based, while their curriculum and school day have been completely restructured.

While a significant improvement on central laboratories, this model still has limitations:

- the computers have to be shared amongst small groups of students, thereby reducing their use as a personal learning tool;

- the computers are desk bound and therefore are only accessible during school hours and to students in their immediate vicinity. This would not so much be an issue in a primary school where students spend most of their time in one classroom, but would be unwieldy in a secondary school.

\section{The introduction of notebook computers into Australian schools}

During the late 1980s notebook computers were introduced into a small number of primary schools to trial classes where they were used mostly for word processing and for the teaching of Logo. However, being an early generation of notebooks they lacked processing power, only had a floppy drive, a small screen, simple word processors and were command line driven. In my view they had a limited positive impact on learning outcomes.

Under the leadership of the Principal, David Loader, in 1989 Methodist Ladies College (MLC, Melbourne, Victoria) [2] became the first school in Australia to introduce personal notebooks on a large scale, and for a number of years it has been a trend setter. They began with year 5 girls who have continued to use them each year, with the result that in 1995 they have spread through to Year 11.

MLC sees itself, and is seen by many other schools, as being highly successful in promoting an innovative and excellent learning environment for their girls. The school is attempting to 'move to a more constructionist approach which is learner centred' [3]. In their model 'computing ... extends the range of media within which teaching can take place', while they see 'the computer ... as a convivial tool with which humans (our students) can develop their personal knowledge'. Its notebook computer programme is the model on which several other schools have based their own programmes.

With the advent of cheaper notebook computers with graphical interfaces there are several schools around Australia, but mostly in the eastern states which have followed MLC's lead in introducing personal computing. 


\section{The vision for Scotch College}

The introduction of computers in schools parallels the introduction of mathematical calculators which were originally of limited power and expensive, and therefore a scarce resource. These only became a successful educational tool once these became cheap, ubiquitous and the personal tool of the individual student and teacher. For the computer to fulfil its potential as an educational tool we realized it too had to be portable and had to be the personal tool of the individual student and teacher (Fig. 1).

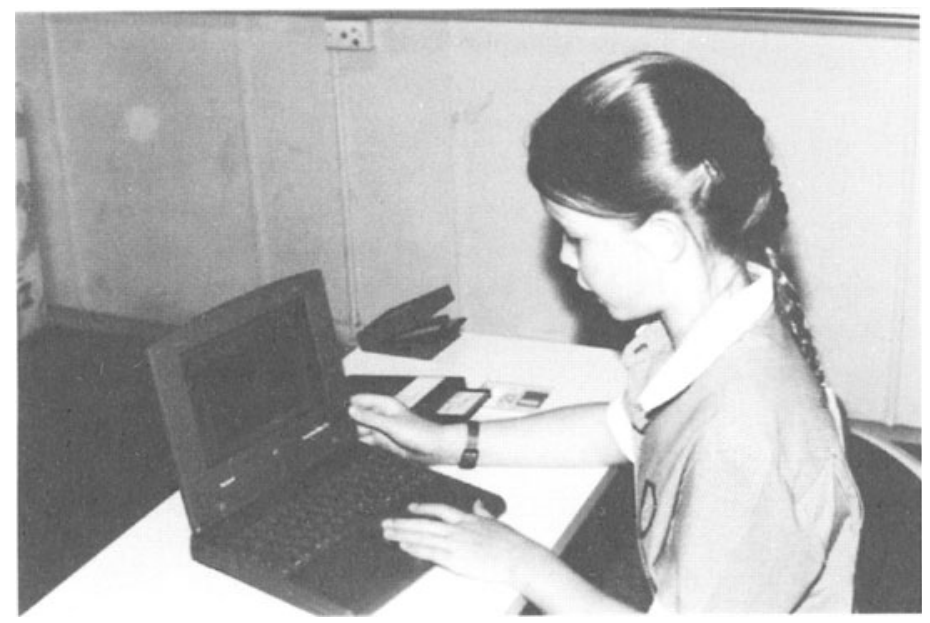

Fig. 1 Ownership, portability, access and contextual use are key issues

The following are aims of the notebook computer programme at Scotch:

- To create, rather than a teaching environment, a classroom as a centre of learning where staff and students cooperate together in the learning process.

- To let the computer act as a learning tool to access, retrieve and critically examine information which can then be positively reconstructed and applied.

- To enable learning to be structured in a flexible, interactive and open-ended way.

- To provide a personal learning environment giving more choice and responsibility to the students for their learning.

- To give all students the opportunity to be autonomous users of technology.

- To open up students at an early age to the vast amounts of information available on the exponentially expanding world-wide electronic communications network. 
- To empower students to be capable of adapting to rapid technological change which has become a feature of our society, and not to become change resistant.

\section{PLANNING FOR THE INTRODUCTION OF A NOTEBOOK PROGRAMME}

The provision of notebooks to staff was a costly exercise. Other schools have expected their staff to share the cost of purchase, but at Scotch those 15 teachers directly connected with the Year 7 programme had computers provided by the school. It was expected of them to quickly learn how to use these and to develop curriculum materials and teaching strategies for use by other teachers.

Also important is installation of classroom equipment, such as printers, networking and mains power, so that students do not have to rely on batteries with their associated recharging problems. Finally, the provision of extra teacher and technical support staff will be vital to the success of the project.

\section{Minimum lead time}

At Scotch the process began about 12 months prior to the beginning of the project. Committees to investigate the idea were set up. A management team was formed from staff with computing and curriculum expertise. The College Council made a formal decision to proceed about 6 months before commencement. I would say this is the minimum time in which to properly plan such a project. Critics have argued that preparation should begin at least a year, and possibly 2-3 years ahead, but the rate of technological change makes long term specific planning difficult. Of course, while it is desirable that staff be skilled computer users prior to the beginning of the programme and that training should begin as soon as possible, it is an unrealistic expectation in many instances.

A key point in our philosophy is that there should not be any special selection of staff-there is no technological literacy prerequisite-the assumption being that, with support, all teachers are capable of working in the new environment. The notebook programme began with the three core Year 7 teachers, two of whom had few computing skills while the third had some. Once the acquisition of these skills became central to their teaching methodologies, i.e. when the computer became highly relevant to them, they quickly (if sometimes painfully!) learnt the appropriate skills. There will, however, always be a range of individual differences in terms of acceptance and implementation across any staff group. 


\section{Support staff}

Support is more than just providing a technician for on-site maintenance of computers. It involves working with teachers and students both in and out of their classrooms, promoting a non-threatening environment in which people are willing to experiment and learn from their mistakes, and helping those who feel daunted by technology. Support staff with good inter-personal skills, a knowledge of classroom practices and with curriculum design experience are needed. Thus two of our more senior teachers have had their jobs redefined to share a 1.6 time allocation for technical, teacher, classroom and curriculum support

\section{Implications for teaching methodologies}

Abandon any thoughts that your current curriculum can remain untouched! Rather look for the ways in which the notebook can enhance the curriculum.

With the notebook the text book is no longer the de facto curriculum. This is well illustrated by an example from Geography. Instead of studying a particular country from a text book containing a limited set of facts which are often out of date, the teacher can gather from electronic online databases contemporary data which can be compiled into units of work and saved onto every student's notebook. Our Humanities and Science teachers have created thematic units of work on, for example the River Murray (Australia's largest river), Antarctica, Earth's Mineral Resources and Communications. To obtain copies of the work, students transfer the units from the network fileserver onto their own computers. The data is therefore immediately available to the student who can search it, rework it into their own format and use it as their own personal resource. The teacher can modify the topic as for example political and economic circumstances change and the material is ready for the next group of students.

Scotch has rejected the idea that the computer itself becomes an object of study. Students are for example not taught HyperCard, but learn to use this application on a 'needs' basis when presenting their research.

\section{THE FIRST YEAR}

\section{Acceptance by students and staff}

As would be expected most children were in favour of using computers, with $90 \%$ of students reporting that they either feel OK or excited. After five weeks, $72 \%$ of the Year $7 \mathrm{~s}$ felt that using the notebook in classes was a real help in completing their work, with another $14 \%$ thinking that it made no difference and $14 \%$ thinking it was a hindrance. 
Given that in general boys are the dominant users of computers at home and in the school's central computer labs (mostly to play games) a concern of mine was that girls would prefer to work in the traditional way and might reject a technological approach to learning. From my observations it is apparent that girls are just as keen as boys to use the notebooks, were equally captivated by the experience of discovering the notebook's potential and found learning through the use of the notebook rewarding.

On the negative side some students have found the notebooks heavy. There has been frustration due to perceived technical faults, some of which are real while many were the result of their inexperience. In particular some students felt initially that they were not doing any real school work and that using pencil and paper was more efficient than using the notebook. Tutoring in keyboarding skills has helped here.

The teachers involved in the programme have so far been enthusiastic about the positive effects of the notebooks in the classrooms, with one teacher stating that she could never go back to the previous model as she finds the new environment exciting and challenging.

While evidence about the effect on learning is subjective, it is generally recognized that students:

- write more;

- are more willing to edit, redraft and improve logical expression;

- are more taskoriented;

- collaborate more with each other.

\section{Practical considerations}

Good technical support has been critical to the smooth running of the programme. Initially students (and staff) went through an exploratory stage where they delved into their computers' systems making changes and adding extra software which caused crashes and other problems. Students have now mostly learnt how to efficiently manage their machines, but there is still a need to replace corrupted systems. Hardware failures have been of two types: electronic and careless handling. Our computer supplier has given excellent technical service which has meant that electronic faults are mostly promptly repaired under warranty. It will be important to have an extended warranty agreement in future years to cater for ongoing repairs. An insurance policy is also essential to cover the situation where students mishandle their computers causing breakages which are not covered under warranty. The school has four spare notebook computers which are lent to students whose machines are undergoing more lengthy repairs. 
Having learnt from the experiences of other schools our students do not need to rely on having fully recharged notebook batteries. Sufficient mains power outlets are provided in each of the main teaching rooms for all students. However the challenge was to allow for flexible seating arrangements. The most popular method of providing power is to have, dangling from the ceiling, a small number of cords attached to power boards each of which has sockets for four computers. Thus classroom layout can be flexible, with no power cords needing to be run across the floor space from the walls.

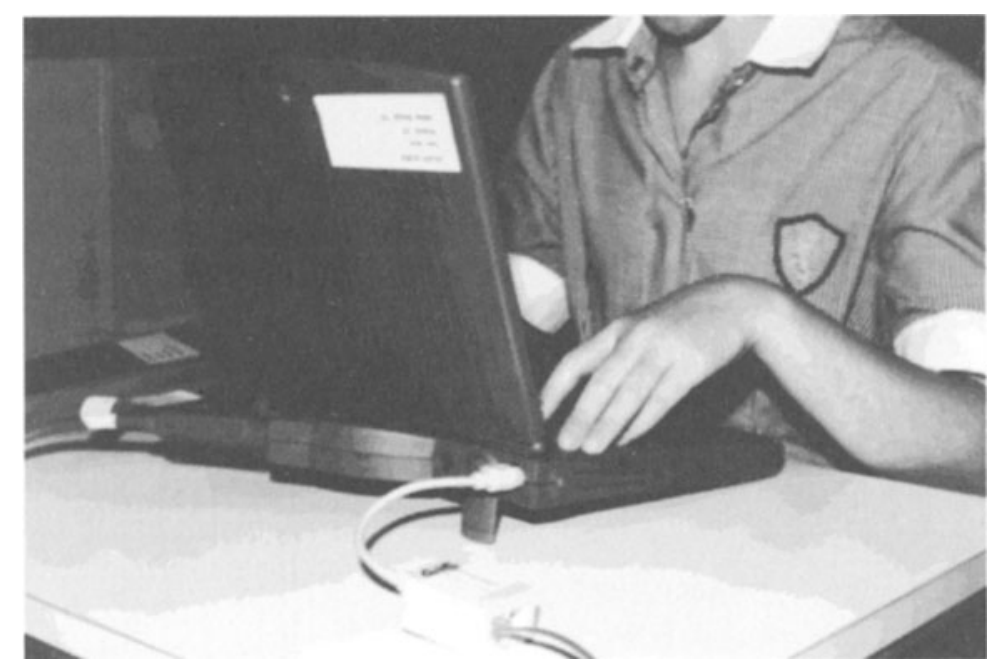

Fig. 2 Connection to the network enables easy access to information and printers

One advantage of Macintosh computers is their inbuilt networking capabilities. To facilitate the transfer of files between teachers and students all main rooms have network outlets attached to a central AppleShare fileserver and to laser printers. When students wish to transfer files to/from their teachers it is a simple matter to plug into an outlet and log on either as a guest or registered user (Fig. 2). Student work to be handed up can either be printed or the files transferred to a teacher's network mailbox. Conversely teachers can prepare units of work as computer files which can be downloaded by students onto their own computers prior to the lesson. The fileserver is also a source of clip art and other resources such as public domain software which all Year 7 and $8 \mathrm{~s}$ can access.

It has been found that one laser printer for every two classrooms is sufficient to enable all users to quickly obtain high quality printouts. 


\section{INTO THE FUTURE: THE SECOND YEAR}

Parents of Year 7 children were surveyed in 1994 with a most positive response, although there were criticisms of some aspects of the programme, the most notable being the need to develop students' keyboarding skills earlier in the year and more intensively. The weight of the notebook received some criticism.

The response from staff and students has mostly been very positive. There has been a fascinating 'flow on' effect through the school this year with a significant increase in interest from teachers from all through the Middle and Senior Schools in how computers can be used for both teaching and administration. There has been great demand for access by staff to notebooks, with the school providing about 30 machines on a permanent basis to staff. Several teachers who have been anti-computing for a long time are now either avid users or are at least a lot more open minded.

In schools over the last 20 years the aim has been to use computers to improve the quality of education, but with limited success because the technology has tended to dominate the user. Computers were expensive and therefore schools could not afford many, they were difficult to use and were fixed to a desk top. Computers only have an impact on education when they become ubiquitous and portable, relatively cheap and can be the permanent possession of the individual user which brings a new sense of freedom and autonomy. Once we are familiar with the technology it can be made to work for us. Ownership, access and contextual use are the key issues relating to the successful cross curriculum integration of computers.

In 1995, with about 170 students in years 7 and 8 using notebook computers, the challenge is to maintain the momentum by continuing to develop curricula, staff computing skills, classroom management practices and infrastructure.

\section{REFERENCES}

1. Alger, A., (1992) A new vision for education: River Oaks Public School. Proceedings of the Tenth Australian Computing in Education Conference, pp. $1-3$.

2. Loader D., (1993) Reconstructing an Australian school. Reflections of a Learning Community: Views on the Introduction of Laptops at MLC, pp. 9-16. 
3. Loader D. and Nevile L., (1993) Educational computing: resourcing the future. Reflections of a Learning Community: Views on the Introduction of Laptops at MLC, pp. 31-35. 